\title{
O ENSINO DE TRADUÇÃO JURÍDICA/JURAMENTADA: UMA PROPOSTA
}

\author{
Teresa Dias Carneiro
}

\section{Introdução}

O aumento do volume de negócios (e litígios) no Brasil, gerando uma crescente demanda de mercado por traduções/versões jurídicas/juramentadas, sem falar na organização de concursos para tradutores juramentados em vários estados da União nos últimos anos, despertou um maior interesse dos alunos dos cursos de formação de tradutores em níveis de graduação e pós-graduação por esse tipo de tradução. Contudo, o ensino de tradução jurídica/juramentada tem suas especificidades e exige determinados conhecimentos e habilidades não necessários ao tradutor de outras áreas, exigindo que os professores se adequem às expectativas e demandas desses alunos a fim de fazer um bom trabalho pedagógico.

Algumas dificuldades se apresentam na elaboração e realização desses cursos: falta de bibliografia didática na área, a necessidade de usar documentos autênticos e não forjados - gerando uma questão delicada de infração do sigilo do tradutor perante seus clientes - e a falta de conhecimento prévio sobre noções de direito por parte dos alunos, além da dificuldade de encontrar profissionais que se disponham a dar esses cursos, abrindo mão de um tempo valioso dedicado ao trabalho.

Com base em minha experiência como professora de tradução jurídica na PUCRio de 2004 a 2013 e em outras instituições, apontarei uma proposta para a criação de um curso de especialização em tradução jurídica, ainda inexistente no Brasil, tomando como apoio a experiência do curso para obtenção do Diploma de Tradutor-Intérprete Jurídico, da Universidade de Lyon, relatada em artigo científico referido abaixo.

Este artigo visa a tratar do terceiro ponto de apoio do tradicional tripé de interesse em tradução: prática, pesquisa e ensino. Acredito que os dois primeiros, por serem objeto de interesse da maioria, serão mais fartamente contemplados nesta edição. Contudo, não se poderia deixar de lado a tão importante questão do ensino, principalmente em uma área florescente, onde ainda há tudo a se fazer e a se questionar. 


\section{Minha experiência pessoal}

A minha reflexão sobre o ensino da tradução jurídica e juramentada se baseia em minha experiência como professora da área nos cursos de tradução da PUC-Rio, em nível de graduação (habilitação em formação de tradutor na graduação de Letras) e cursos de extensão universitária oferecidos pela Coordenação Central de Extensão (PUC-Rio), como o Curso de Formação de Tradutores, e cursos livres de tradução jurídica e preparatórios para o concurso de tradutor juramentado, no par de línguas inglês/português, além de algumas incursões em outras instituições de classe. A tradução jurídica faz parte da minha atividade profissional diária, já que sou tradutora juramentada do idioma inglês no Rio de Janeiro.

Na graduação em Letras, habilitação em Formação de Tradutor, na PUC-Rio, existe uma disciplina eletiva sobre tradução jurídica/juramentada. A disciplina é oferecida uma vez a cada três períodos, em média, e ocorre em rodízio com outras duas disciplinas eletivas, tradução para legendagem e ferramentas de tradução. Os alunos, para se inscreverem na disciplina, precisam já ter cursado as disciplinas de tradução técnica, com aproveitamento. Portanto, são alunos a partir do quinto período, muitos já no final do curso, não sendo, portanto, alunos iniciantes em tradução, apesar de a maioria ser não profissional. Ainda assim, esses alunos, num primeiro momento, encontram dificuldade com a terminologia específica da área e o estilo da redação jurídica, e, num segundo momento, em perceber como a diferença entre os sistemas jurídicos do Brasil (civil law) e dos países de língua inglesa (common law) causa impacto sobre suas soluções tradutórias, por não equivalência e intraduzibilidade. A minha primeira providência com esses alunos foi sensibilizá-los para que começassem a desenvolver uma percepção de que alguns termos da linguagem comum (por exemplo, company, copy, partner etc.), ou termos que eles já conheciam de outras áreas técnicas (por exemplo, liability, loss, claim, etc.), assumem um significado mais restritivo na linguagem jurídica, tendo que ser traduzidos por termos específicos. Para isso, antes mesmo de começar a pensar em traduzir textos jurídicos, dispunha-me a ler textos jurídicos em inglês e português do mesmo tipo de documento ou da mesma área (direito comercial ou societário, por exemplo) com eles, para que vissem as diferenças e começassem a depreender o que seria a terminologia específica da área. Em geral, os termos que os alunos nunca viram antes são fáceis de reconhecer, a dificuldade maior 
está mesmo nos termos que já conhecem da linguagem comum ou de outras áreas do conhecimento, mas que no direito constituem uma nova linguagem de especialidade.

Após essas aulas iniciais de sensibilização, começava a propor traduções de documentos pequenos e mais simples, como procurações, certidões e certificados, aumentando progressivamente a dificuldade e extensão, e variando as áreas do direito, do direito comercial e societário, passando para o direito contratual, de família e documentos híbridos que tratam de direito e outra área do conhecimento, como finanças, engenharia, seguros/resseguros, óleo e gás etc. A cada nova tradução proposta para a aula seguinte, fazíamos uma espécie de aquecimento, com uma leitura inicial e levantamento da terminologia. Se fosse preciso explicar algum conceito jurídico desconhecido, era nesse momento que tratava das dúvidas de conteúdo suscitadas pelo texto.

$\mathrm{Na}$ discussão sobre as traduções, procurava utilizar técnicas pedagógicas diferentes. Ou escolhia a tradução de algum aluno, não identificada, que me tivesse sido enviada por e-mail previamente, para ser projetada na tela e discutida em grupo, ou os alunos se reuniam em grupos de dois para trocarem suas traduções e discutirem entre si antes da discussão no grupo grande, ou trazia uma tradução minha ou de outro profissional, não para servir de modelo ou "gabarito", mas para que eles percebessem qual é o nível de uma tradução profissional, nível a que eles deveriam almejar alcançar para ter chances de inserção nesse mercado de trabalho, ou ainda produzíamos uma tradução em grupo na sala de aula. No final de cada discussão, uma versão final revisada da tradução discutida pelo grupo era enviada por e-mail para os alunos ou postada na pasta online da disciplina. Mais recentemente comecei a usar o recurso do Dropbox ou a Plataforma Moodle para compartilhamento de arquivos, com sucesso. O curso dura um semestre letivo (quatro meses), tempo suficiente para acompanhar uma evolução muito grande no desempenho dos alunos do início ao final da disciplina.

Já no curso de Formação de Tradutores, em nível de extensão (pós-graduação lato sensu), no qual ministrei módulos diversos, não havia um módulo específico de tradução jurídica. Contudo, sempre procurei introduzir algumas aulas de tradução jurídica no módulo de Tradução Empresarial/Comercial e de tradução de textos de direito no módulo de Tradução de Ciências Sociais e Humanas. Esse curso está sendo reformulado no momento e será oferecido a partir do primeiro semestre de 2015 como 
Curso de Especialização em Tradução, em novos moldes, contendo um módulo exclusivo de Tradução Jurídica.

Contudo, a experiência mais recompensadora que tive com ensino de tradução jurídica foi o curso livre "Princípios e Prática em Tradução Jurídica", ministrado com a colega Regina Lyra. Apesar de ambas já darmos aulas de tradução jurídica e, no caso da Regina, que é advogada, de Noções de Direito para Tradutores, decidimos fazer uma experiência nova e inovadora, pelo menos no âmbito dos cursos de extensão da PUCRio. Intercalamos aulas de tradução e noções de direito em áreas variadas, mas principalmente nas que sentimos ter mais demanda de trabalho no mercado, ministradas aos sábados pela manhã, para que um maior número de pessoas (profissionais autônomos ou com horário de trabalho rígido) pudessem comparecer. Estendemos o público-alvo, desta vez contemplando não só tradutores, mas também alunos da graduação em tradução na PUC-Rio, advogados e estudantes de advocacia, que traduzem em seus estágios. O resultado foi muito animador e produtivo. As discussões foram acaloradas, com aportes vindos de quem já traduzia profissionalmente, quem era tradutor iniciante, mas com formação acadêmica em tradução, advogados atuantes e estudantes de advocacia. Cada um contribuiu de sua maneira, as dúvidas de uns foram dirimidas por outros e eu, pela primeira vez, acabei agindo mais como intermediadora ou estimuladora das discussões do que propriamente como professora em sua função tradicional. O curso durou de setembro a dezembro de 2013. Compartilhamos materiais e glossários, acessamos sites de interesse na Internet, avaliamos fontes de pesquisa e documentação, além de termos discutido soluções de tradução apresentadas pelos alunos. Em suma, os resultados alcançados apontam para uma possível estratégia de ensino, mais coadunada com os novos tempos de compartilhamento de informação rápida, mas nem sempre confiável. O fato de ter colocado o andamento do curso também sob a responsabilidade dos alunos estimulou a participação deles. Por outro lado, esse formato de curso, uma tentativa de aplicação da prática exploratória no ensino de tradução jurídica, cansa mais o professor, que se vê em uma posição de não controle total do andamento da aula, com a mediação de um grupo de alunos de perfis e backgrounds tão diversos.

Com base na minha experiência, em situações docentes tão diferentes, posso tirar algumas conclusões que talvez venham de encontro ao senso comum. Em primeiro 
lugar, tradução jurídica não é só para advogados, mas uma área de trabalho muito dinâmica para os tradutores técnicos que se interessem por essa vertente, que, com o treinamento adequado e capacidade de pesquisa competente, podem trabalhar na área com muitas chances de sucesso. Se esses tradutores forem capazes de fazer versão para o idioma estrangeiro, tanto melhor, pois este é um mercado amplo e em florescimento. Em segundo lugar, é possível estimular alunos de graduação em tradução a conseguir bons resultados, inclusive com inserção real no mercado de trabalho, para atuar em uma área técnica árida e pouco excitante. Em terceiro lugar, é possível elaborar cursos de tradução jurídica/inglês jurídico diferentes em escopo e extensão, moldados às necessidades dos públicos-alvo e instituições diferentes, dentro e fora da academia. Em quarto lugar, é possível juntar, numa mesma turma, tradutores (profissionais ou iniciantes) e advogados (formados ou em formação) e conseguir resultados produtivos para todos. Em cada uma das situações docentes descritas, a aquisição de conhecimentos se deu de maneira particular, autônoma e individual, em função das competências e aptidões de cada um, mas os resultados foram palpáveis dentro da proposta de cada curso.

Conclui-se, então, que um curso de tradução jurídica eficaz deve ser mais amplo do que a tradução propriamente dita, abrangendo noções de direito para não advogados, linguagem de especialidade na língua de partida e de chegada (no meu caso, português jurídico e inglês jurídico) e noções de direito comparado nos sistema de origem e alvo. Isso exige que um curso mais completo tenha que ter duração razoável, o que não invalida esforços para se organizar cursos introdutórios de tradução jurídica, de aprofundamento ou reciclagem, que possam servir para suscitar uma curiosidade, desenvolver uma competência ou abrir toda uma possibilidade de vida profissional.

Apesar de os cursos de tradução jurídica poderem assumir durações variadas, com resultados palpáveis, que podem ser mensuráveis com apresentação de dados concretos, com base em amostras de exercícios e estatísticas de resultados desses exercícios (e hoje, com a utilização das novas tecnologias no ensino, ficou bem mais fácil fazer a mensuração do que no passado, com a proposição e aferição de testes e tarefas no Moodle), gostaria de aproveitar o espaço deste artigo para apresentar uma proposta efetiva de elaboração de uma grade curricular para um curso de especialização de tradução jurídica, com carga horária de 360 horas. Desconheço a existência de um 
curso desse tipo no Brasil, tendo ciência de cursos como os que ministrei e não de uma proposição de mais fôlego e duração. A formação de tradutores da área jurídica no Brasil ainda é inconsistente, tendo o tradutor interessado que fazer vários cursos livres ou acadêmicos, se tiver sorte de na sua cidade haver uma universidade que os ofereça, ou à distância, como os que alguns tradutores individuais ministram. Antes de apresentar minha proposta, porém, seria de interesse observar a experiência de um curso análogo na Universidade de Lyon, para servir de apoio a minhas proposições, e não como parâmetro de comparação, pois não participei desse curso, tendo tomado contato apenas por meio de artigos científicos, e ainda ressalvando-se as diferenças culturais e acadêmicas entre os dois países. Nunca é possível transplantar experiências internacionais, sem análise crítica e aclimatação à nossa realidade.

\section{Uma experiência de ensino de tradução jurídica na França}

Por meio de dois artigos de autoria de Del Bove (2010, 2013), tomei contato com a experiência do curso de formação contínua $(b a c+2)$ em tradução para obtenção do Diploma de Tradutor-Intérprete Jurídico, da Universidade de Lyon, iniciado em 2009. O alunado em referência é, em sua grande maioria, composto por tradutores/intérpretes profissionais, com idade média de 42 anos, oriundo dos cursos de Letras (Línguas Estrangeiras Aplicadas), alguns com experiência de trabalho em tribunais. Na primeira turma, não havia nenhum aluno oriundo de cursos de direito, sendo que alguns haviam feito cursos de formação pontuais em noções de direito, no âmbito da SFT (Société Française de Traducteurs). A expectativa desses alunos não é se tornarem juristas ou advogados, mas adquirir conhecimentos fundamentais a respeito dos sistemas jurídicos e organizações jurisdicionais dos países correspondentes a suas línguas de trabalho (Del Bove, 2013). A autora também reforça a ideia de que não é necessário ser jurista para fazer tradução jurídica, com base em declaração de Judith Lavoie, professora da Universidade de Montreal:

Como indica Judith Lavoie, não é preciso ser jurista para traduzir direito, contudo "[...] é claro que o aluno(a) formado(a) em tradução jurídica deverá, como todo tradutor profissional, conhecer as bases do domínio no qual pretende exercer sua profissão; em outras palavras, o fato de ter competências em tradução não isenta o futuro tradutor de deter conhecimentos de direito, um não excluindo o outro" (Lavoie 2003: 396) (Del 
Bove, 2013, p. 3). ${ }^{1}$

A primeira constatação diante de um texto jurídico é que sua tradução exige um duplo conhecimento ao mesmo tempo jurídico e cultural dos países das línguas de partida e de chegada, já que a passagem de um sistema jurídico para outro pode ser particularmente delicada no caso de países que não pertençam à mesma família do direito, como é o caso dos EUA e Grã-Bretanha (common law) e a França (tradição civilista). Assim sendo, o curso e o diploma foram pensados para atingir três objetivos principais: (1) completar a formação generalista dos tradutores por uma iniciação ao direito francês e estrangeiro, fornecendo aos participantes os fundamentos epistemológicos indispensáveis à operação tradutória, como a lógica e os princípios jurídicos, a terminologia e a sintaxe dos textos legais e decisões judiciárias; (2) fornecer aos tradutores-alunos ferramentas transponíveis a qualquer situação para lhes permitir compreender e analisar melhor um texto de direito ou jurídico, para estarem capacitados a traduzi-lo bem; (3) tomar contato com o mundo da tradução (professores e colegas) e o ambiente judiciário (profissionais do direito, advogados, tabeliães, magistrados, escreventes). O curso, portanto, possui uma forte visada nocional (noções de direito, organização jurisdicional e direito comparado, perfazendo cerca de $54 \%$ da carga horária), uma visada terminológica (terminologia jurídica, oficinas de tradução jurídica e criação de glossário de falsos cognatos e glossário de termos jurídicos, perfazendo cerca de $30 \%$ da carga horária) e uma visada comunicativa e prática (orientada para o exercício profissional, perfazendo cerca de $14 \%$ da carga horária), sendo a carga horária total de 204 horas, cursada em 2 anos.

O primeiro objetivo está em perfeita consonância com o aconselhamento dado por Bocquet: "A iniciação ao direito para tradutores é centrada no aprendizado e no domínio da lógica do direito, porque ela é também a lógica de sua linguagem e de seu discurso" (Bocquet, 2008, p. 89). Nesse sentido, as especificidades de cada sistema jurídico, como a lógica e os princípios jurídicos, a terminologia, os textos da lei e as decisões judiciárias, são encaradas como fundamentos epistemológicos indispensáveis à operação tradutória. Como se vê, noções de direito e prática tradutória andam de mãos dadas nas bases desse curso.

\footnotetext{
${ }^{1}$ As traduções de trechos retirados da literatura estrangeira são de minha autoria.
} 
Segundo o relato da autora, a maior dificuldade foi discernir quais campos do direito deveriam ser contemplados, já que a disciplina é muito complexa pela diversidade de dados e a grande variedade de áreas agrupadas sob a rubrica do direito. Acabou-se optando por cobrir áreas em que a tradução é mais requisitada, como direito civil, direito internacional privado, direito europeu, direito empresarial, direito penal e direito comparado, incluindo o estudo comparativo dos sistemas jurídicos nos países das línguas envolvidas, mas deixando de lado áreas como direito autoral e propriedade intelectual. Este estudo comparativo das várias tradições jurídicas é visto como uma abordagem pedagógica prévia à tradução, bem como a pesquisa documental feita em documentos originais redigidos nas línguas de partida.

Em seguida, é desenvolvido o segundo pilar do curso, o estudo da terminologia jurídica francesa em contexto e uma oficina de linguagem jurídica estrangeira, atentando-se para a não isomorfia dos sistemas em presença. Nos exercícios, os alunos são levados a se conscientizarem das dificuldades da tarefa e optarem por se sujeitar às restrições e à economia da língua de partida ou da língua de chegada. Assim, Del Bove ressalta:

Para não entrar num debate que não é nosso objetivo aqui, insistiremos, sobretudo, na importância, para todo tradutor, de estar consciente dessa dupla restrição, linguística e jurídica, na medida em que sua tarefa lhe impõe, de um lado, respeitar o conteúdo original de cada sistema jurídico e, de outro, estabelecer um tipo de jogo de espelhos não deformante entre os dois sistemas em presença (Del Bove 2010, p. 10).

As oficinas de tradução suscitam uma teorização mínima sobre procedimentos tradutórios em função das situações encontradas: (1) equivalência perfeita quando um termo corresponde a outro, o que permite uma transposição palavra por palavra; (2) equivalência parcial quando os diferentes termos não apresentam o mesmo número de traços semânticos, em que os termos de um mesmo par possuem um valor diferente no sistema nocional de seu direito respectivo, gerando um procedimento de equivalência funcional; e (3) ausência de equivalência, que faz recorrer à criação, com todas as precauções que isso supõe (empréstimos com ou sem aspas ou itálico, decalque ou perífrase ou glosa empregadas principalmente para transpor os nomes de jurisdições de um sistema para o outro).

As principais conclusões trazidas por essa experiência de ensino de tradução 
especializada na área jurídica, visando a formar tradutores jurídicos prontos para atuarem no mercado de trabalho, foram que esse tipo de curso se volta para profissionais ou tradutores em vias de se tornarem profissionais, e não para tradutores iniciantes, devido à complexidade da matéria. Segundo a autora, o ideal é que os tradutores já tenham tido experiência com outros ramos da tradução antes de se iniciarem nessa área. Outra conclusão a que se chegou é que o corpo docente deve ser híbrido: os instrutores dos módulos nocionais são professores de direito, com a preocupação de utilizarem uma linguagem simples, mas não simplista, endereçada a não-juristas. Os instrutores de terminologia jurídica são advogados. Para as oficinas de tradução, os responsáveis pelo ensino são professores de linguagem jurídica na universidade, especialistas em direito comparado e tradutores profissionais e professores de tradução. Dois pontos positivos foram ressaltados: o trabalho em pequenos grupos e a fase de comunicação, que pôs em contato os profissionais da tradução e os profissionais do direito, que se dispuseram a explicar ou esclarecer os problemas de compreensão ou as incertezas suscitadas pelos textos jurídicos. Um ponto negativo foi apontado pela autora: a impossibilidade de contemplar línguas menos conhecidas, mas demandadas, na oficina de linguagem jurídica por falta de estrutura adequada para atender a muitas línguas no mesmo curso. Na primeira turma do curso, iniciada em 2009, a línguas de trabalho foram espanhol, inglês, russo, polonês, árabe, além do francês, obviamente. Outro ponto lamentável foi não ter sido possível trabalhar suficientemente com os alunos na área das pesquisas documentais online, para lhes permitir encontrar elementos mais rapidamente para a contextualização de um texto jurídico. Este aspecto, segundo a autora, seria mais aprofundado nas novas turmas do curso. Em linhas gerais, o balanço foi positivo e a autora diz que se pretendem formar novas turmas, dando continuidade ao projeto.

\section{Uma proposta brasileira}

Com base no relato da professora da Universidade de Lyon e minhas experiências próprias de ensino de tradução jurídica, percebo alguns pontos de contato e diferenças, que podem embasar uma proposta brasileira. Em primeiro lugar, devido à dificuldade do conteúdo e a maturidade necessária por parte do alunado, no Brasil, um curso desse tipo deveria ser realizado nos moldes de uma especialização (e não de 
formação contínua, como na França, ou de habilitação em curso de graduação), isto é, para portadores de diploma de curso superior. Além disso, os candidatos, com formações acadêmicas diversas, deveriam passar por uma seleção prévia, com base em análise de currículo, comprovação de experiência como tradutores e de proficiência na língua de partida e de chegada. Outra diferença em relação ao curso francês é que os cursos de especialização no Brasil possuem carga horária maior por serem uma pósgraduação lato sensu, a saber 360 horas (normalmente com duração de um ano e meio a dois anos, a depender da carga horária semanal). Diante das dificuldades cada vez maiores de mobilidade urbana nos grandes centros no Brasil (e não vejo como dar um curso desse tipo em uma cidade do interior, já que a demanda por trabalho está mais nos grandes centros), proponho que $40 \%$ do curso seja dado à distância e $60 \%$ presencial. As aulas de conteúdo nocional e de aquecimento às traduções poderiam ser presenciais e os exercícios e correções poderiam ser feitos à distância, com as discussões sobre traduções feitas em fóruns ou blogs, a criação de glossários em ferramentas Wiki, o levantamento terminológico em software de pesquisa em corpus e a proposição e a entrega de tarefas na plataforma Moodle. Tudo isso pode ser feito à distância, suavizando a carga presencial. Como uma primeira experiência, o curso poderia ser oferecido para o par de línguas inglês-português, que é a maior demanda do nosso mercado, com prática tanto de tradução quanto de versão. O corpo docente seria composto por profissionais do Direito e de Letras, com foco em tradução e terminologia. $\mathrm{O}$ foco de visita e comunicação com os órgãos judiciais apresentado na proposta francesa seria incorporado à proposta brasileira. E, ainda, incorporado um módulo de interpretação em juízo, com prática de interpretação consecutiva básica. Desconheço qualquer curso no Brasil que tenha essa preocupação de formação do intérprete comercial, como é chamado entre nós.

No caso do curso da Universidade de Lyon, a carga horária nocional precede a carga horária terminológica/tradutória. $\mathrm{Na}$ minha proposta, as duas vertentes andariam simultaneamente, com módulos superpostos. Contudo, parece que as duas propostas se baseiam na mesma premissa: não é possível traduzir textos jurídicos sem um bom conhecimento da área e das diferenças entre os sistemas jurídicos dos países das línguas envolvidas. Em conclusão, não é preciso ser jurista, mas ter conhecimentos de quase jurista, para bem traduzir textos jurídicos. Ora, isso é um trabalho de uma vida, que não 
se circunscreve à duração de um curso, mesmo sendo de dois anos. A ideia de formação contínua que está por trás da experiência francesa, também embasaria a minha proposta: é importante ensinar boas técnicas de pesquisa na Internet e fora dela, para criar hábitos e uma competência que os tradutores levariam para sua vida inteira. Não só é preciso conhecer noções de direito e terminologia - e ter muitas horas de prática - , como também estar atento às modificações que o direito vem sofrendo com o advento de novas necessidades, novas tecnologias e novos desdobramentos dos mecanismos extrajudiciais de resolução de conflitos.

\section{Referências bibliográficas}

BOCQUET, C. La traduction juridique: fondement et méthode. Bruxelles: De Boeck, 2008.

DEL BOVE, M. C. Exemple de formation en traduction juridique, 2010. Disponível em: <http://www.initerm.net/public/langues\%20de\%20sp\%C3\%A9cialit\%C3\%A9/col loque/Marion_Charret_Del_Bove.pdf $>$. Acesso em: 15 ago. 2014.

DEL BOVE, M. C. Le diplôme universitaire de traducteur interprète juridique, un exemple de formation continue en traduction juridique, 2013. Disponível em: http://hal-univ-lyon3.archivesouvertes.fr/docs/00/98/00/80/PDF/Le_diplome_universitaire_de_traducteur_inter prete_juridique_un_exemple_de_formation_continue_en_traduction_juridique.pdf . Acesso em 15 ago. 2014. 